\title{
The management of opioid dependence during pregnancy in rural and remote settings
}

\author{
Naana Afua Jumah MD DPhil, Lisa Graves MD, Meldon Kahan MD MHSc
}

$\mathrm{N}$ onmedical use of prescription opioids is a growing problem in Canada; in 2011, it had the highest per capita consumption of oxycodone in the world. ${ }^{1}$ When a woman with opioid dependence becomes pregnant, adequate management of the addiction is of critical importance for the well-being of both mother and child. Untreated opioid addiction has been associated with risk-taking behaviour, preterm delivery, low birth weight and stillbirth. ${ }^{2,3}$ Ideally, antenatal care for women with opioid dependence is accomplished with multidisciplinary care, including treatment of the addiction. ${ }^{4,5}$ However, women who live in rural and remote communities may not have access to such care or may have challenges accessing it. ${ }^{6}$

Comprehensive guidelines to manage the care of pregnant women with opioid dependence who live in rural or remote communities do not currently exist. This absence, in addition to a lack of resources, a lack of training in the treatment of addiction in pregnancy and providers' discomfort with opiate substitution therapy in pregnancy, has contributed to wide variations in the quality of care these women receive.

We evaluate strategies for the treatment of opioid dependency in pregnancy applicable to rural and remote settings, including methadone maintenance therapy, buprenorphine maintenance, slow-release morphine maintenance and opioid detoxification (Box 1). ${ }^{7}$ Special consideration is given to members of Canada's Aborig inal population. Very little literature exists regarding the management of polysubstance use in pregnancy, and a full discussion of the issue is beyond the scope of this review.

\section{What are the patterns of opioid dependence in rural and remote areas of Canada?}

Statistics Canada defines a rural community as having less than 10000 people, with less than $30 \%$ of the population commuting to a city of 100000 people or more for work. ${ }^{8}$ However, the Canadian Medical Association defines rural as areas in which physicians have high call requirements, there are long distances to secondary and tertiary care centres, there is a lack of specialist care and there are insufficient health care providers. $^{9}$

Given these differing definitions, the descriptions of pregnant women with opioid dependence who reside in these areas vary widely in terms of socioeconomic status, ethnic diversity and proximity to urban resources. ${ }^{10}$ Heroin is the most commonly reported opioid used by pregnant women living in rural and remote communities, ${ }^{2,10,11}$ but the nonmedical use of prescription opioids is increasing. ${ }^{10,11}$ Regardless of the opioid in use, treatment strategies for pregnant women in these communities primarily involve methadone maintenance. ${ }^{2,3}$

\section{What is the recommended treatment for opioid dependence during pregnancy?}

The management of opioid dependence in pregnancy in rural and remote settings requires special consideration (Boxes 2 and 3).

Methadone maintenance therapy is the gold standard for treating opioid dependence in pregnancy. ${ }^{12,13}$ Numerous studies have shown that, in pregnant women who use heroin, methadone is associated with more visits for antenatal care, longer gestations, higher birth weights, lower rates of HIV infection, higher rates of infant discharge home in care of the mother and lower rates of relapse compared
Competing interests: Meldon Kahan has received nonfinancial support from Reckitt Benckiser. No other competing interests were declared.

This article has been peer reviewed.

Correspondence to: Naana Afua Jumah, njumah@nosm.ca

CMAJ 2015. DOI:10.1503 /cmaj.131723
- KEY POINTS
more common, and members of Canada's Aboriginal population are
disproportionately affected.
- Methadone maintenance therapy has logistic limitations in rural and
remote settings, but buprenorphine and slow-release morphine
maintenance therapies are feasible alternatives.
- Opioid detoxification in pregnancy is associated with high rates of
relapse and should only be offered if a comprehensive rehabilitation
program is available.
- Treatment of opioid dependence and rehabilitation services should be

- Treatment of opioid dependence and rehabilitation services should b
provided to all women during pregnancy and the postpartum period. 
with no treatment or detoxification. ${ }^{4,5}$

Methadone has important logistical limitations that prohibit its use in resource-limited locations. Methadone can only be prescribed by physicians who hold a special license. ${ }^{14}$ Because of the high risk of overdose at the start of treatment, methadone must be dispensed daily and ingested under the observation of a licensed pharmacist at a registered pharmacy. ${ }^{15}$ Because many rural and remote communities are unable to provide this service, methadone is not offered.

\section{What are the alternatives to methadone maintenance therapy?}

Observational studies have shown buprenorphine maintenance therapy to be a safe and efficacious alternative to methadone for the treatment of opioid dependence in pregnant women. ${ }^{16,17}$ Recent randomized controlled trials have shown that buprenorphine and methadone cause similar reductions in maternal opioid use and similar

\section{Box 1: Evidence used in this review}

We conducted a literature search of PubMed, Embase and JSTOR between July 2013 and September 2013 for the following terms: "pregnancy," "pregnant," "rural," "remote," "non-urban," "nonurban," "Aboriginal," "Indigenous," "First Nations," "Inuit," "opiate," "opioid," "methadone," "buprenorphine," "slow release," "morphine," "detoxification," "taper" and "wean." We did not limit our search to a specific period or language. In addition, we searched government and nongovernmental organization sources including Statistics Canada, Health Canada, First Nations and Inuit Health Branch, National Aboriginal Health Organization and NishnawbeAski Nation. If an abstract was deemed to be relevant, the article was read in full. We reviewed the references in each article to identify additional relevant papers. The details of our search strategies and retrieved articles are available on request. We reported the quality of the evidence according to criteria set forth by the Canadian Task Force on Preventive Health Care. ${ }^{7}$

\section{Box 2: Applying the results of this review in clinical practice}

- Methadone maintenance therapy should be started for all women with opioid dependence in pregnancy (I-A).

- If methadone is not available, maintenance therapy should be started with buprenorphine (I-A).

- If methadone and buprenorphine are not available, maintenance therapy should be start with slow-release morphine (I-A).

- If a woman is already receiving buprenorphine plus naloxone maintenance therapy before pregnancy, she may continue to do so during pregnancy (II-2B) or change to buprenorphine alone if available (I-A).

- Detoxification should only be used at the patient's request (II-2A). The patient should be counselled about the high failure rate of detoxification (II-2A), the risks of overdose with failure of detoxification and the option to start maintenance therapy at any point should she relapse (III-B).

- All pregnant women with opioid dependence should be offered maintenance therapy and rehabilitation services postpartum (III-B).

- Methadone, buprenorphine (Subutex), buprenorphine + naloxone (Suboxone) and slow-release morphine (Kadian) are all available in Canada. birth and neonatal outcomes, and that buprenorphine is associated with decreased severity of symptoms of neonatal abstinence syndrome. ${ }^{18,19}$ A case series describing 10 women who took buprenorphine plus naloxone maintenance therapy showed outcomes similar to those of buprenorphine alone. ${ }^{20}$

Buprenorphine is a partial $\mu$-opioid receptor agonist that has a lower risk of fatal overdose than full $\mu$-opioid agonists such as methadone. Buprenorphine may precipitate withdrawal if caution is not exercised at the start of treatment. The drug may also incompletely treat withdrawal symptoms, putting patients at risk for ongoing use of illicit drugs to manage their symptoms. Furthermore, buprenorphine may be less effective than methadone at retaining patients in treatment if they used opioids intravenously. ${ }^{21,22}$ Unlike methadone, Health Canada does not require an exemption to prescribe buprenorphine; however, outside of Ontario and Quebec, public funding of buprenorphine is restricted to physicians with a methadone license. ${ }^{23}$

The buprenorphine formulation now includes naloxone, which is intended to deter misuse. Addiction literature often cites naloxone as a possible teratogen and warns against its use in pregnancy. ${ }^{24}$ However, the United States Food and Drug Administration classifies naloxone as a pregnancy category $\mathrm{B}$ drug, meaning that there have been no reports of teratogenicity in humans or animals. ${ }^{25}$ The greater concern in pregnant women with opioid dependence is naloxone's ability to precipitate withdrawal if taken intravenously or intranasally. Naloxone has minimal buccal or sublingual absorption. ${ }^{26,27}$ As previously described, acute opioid withdrawal is associated with morbidity for both the woman and her fetus.

\section{What if methadone and buprenorphine are not available?}

Slow-release morphine maintenance therapy has been proposed as an alternative to methadone when the latter is not available. ${ }^{28}$ In resourcelimited areas, slow-release morphine may be more accessible because a special license to prescribe it is not required, and it is readily available in pharmacies. Accessibility is also the most notable drawback of morphine because it is more easily acquired and diverted than methadone. In addition, morphine is more easily injected than methadone, and it cannot be distinguished from heroin in a urine screening, limiting the usefulness of urine screens during treatment.

We identified one prospective, randomized 
study that compared methadone with slowrelease morphine maintenance that included 24 women in each arm. ${ }^{29}$ No difference in neonatal outcomes, including neonatal abstinence syndrome, was seen between the two groups. Mothers taking slow-release morphine had a significant decrease in the use of benzodiazepines and other opiates. Two smaller observational studies showed that pregnant women taking slow-release morphine were significantly less likely to use benzodiazepines or additional opioids while undergoing treatment. ${ }^{30,31}$ A hypothesized advantage of morphine is a decreased duration of neonatal abstinence syndrome owing to its shorter half-life compared with methadone. ${ }^{30}$

\section{Is neonatal abstinence syndrome a problem?}

Neonatal abstinence syndrome has not been associated with long-term neurodevelopmental harms in children, whereas ongoing maternal substance use is associated with poor developmental outcomes in children. ${ }^{32}$ The syndrome is time-limited as the infant withdraws from in utero exposure to an opioid. No association has been found between a mother's methadone dose and the severity of symptoms of neonatal abstinence syndrome. ${ }^{33,34}$ Furthermore, pharmacodynamic studies show that escalations in dose are needed to maintain the therapeutic effect as pregnancy progresses owing to changes in methadone metabolism. ${ }^{35}$

\section{Is there a role for detoxification in pregnancy?}

An early observational study showed similar outcomes among pregnant women who used heroin and had undergone medical detoxification compared with a control group consisting of pregnant women with no opioid dependency. ${ }^{36}$ However, medical detoxification was deemed a failure because of its inability to provide durable abstinence. This study was contrasted by two early case reports documenting adverse pregnancy outcomes in women undergoing acute heroin withdrawal rather than medically managed detoxification. ${ }^{37,38}$ This contrasting evidence led to a resurgence of interest in medical detoxification in pregnancy in the 1990s. Complete opioid detoxification was recommended in a 2002 publication, with the aim of eliminating neonatal abstinence syndrome. ${ }^{39}$

Among the five retrospective case series involving women with heroin addiction, there is no consensus on the rate of methadone taper or the superiority of inpatient versus outpatient detoxification (Box 4). ${ }^{40-44}$ Although the literature cites concerns for increased rates of miscarriage with detoxification during the first trimester and increased rates of preterm labour with detoxification during the third trimester, ${ }^{45,46}$ this effect was not shown. ${ }^{40,43}$ Neonatal outcomes, when reported, were inconsistent. In addition, maternal heroin use postpartum and ongoing addiction treatment postpartum were not reported.

We recommend that acute detoxification in pregnancy should be abandoned, given the evidence, with the exception of women who decline opioid substitution therapy. In this circumstance, a woman should be given the opportunity to transfer into an opioid substitution program at any time if she elects to do so or if she is unable to successfully taper off of opioids. Postpartum rehabilitation services must be provided for all women, particularly those who have chosen abstinence.

\section{How does opioid dependence in pregnancy affect rural or remote Aboriginal populations?}

Canada's Aboriginal communities are predominantly in rural and remote areas and are disproportionately affected by opioid dependence, with rates between $50 \%$ and $80 \% .{ }^{47}$ Nonmedical use of prescription opioids is more common than heroin use, ${ }^{47,48}$ and the route of exposure is more often oral than intravenous. ${ }^{48}$ A 2012 descriptive report from Northwestern Ontario questioned whether the benefits seen with methadone in people who use heroin are applicable in remote Aboriginal communities where women engage in binge use of prescription opioids owing to

\section{Box 3: Resources for clinicians}

- Wong S, Ordean A, Kahan M. Substance abuse in pregnancy. J Obstet Gynaecol Can 2011;33:367-84. ${ }^{12}$

- American College of Obstetricians and Gynecologists. Opioid abuse, dependence and addiction in pregnancy. Committee opinion 254. Obstet Gynecol 2012;119:1070-71. ${ }^{13}$

- Chase C. Supporting women using opiates in pregnancy: a guideline for primary care providers. Toronto: The Centre for Addiction and Mental Health Knowledge Exchange; 2011. Available: http://knowledgex.camh .net/opioid_alert/2012/Documents/supporting_women_opiates_ pregnancy511.pdf 28

- Methadone program. Ottawa: Health Canada; 2011. Available: www.hc-sc.gc.ca/hc-ps/substancontrol/exemptions/methadone-eng.php ${ }^{14}$

- Hanford C. Buprenorphine/naloxone for opioid dependence: clinical practice guideline. Toronto: Centre for Addiction and Mental Health; $2012 .^{23}$ 
intermittent drug availability rather than daily use of heroin. ${ }^{49}$ No evidence supports or refutes this claim.

A prevalence study involving First Nations women receiving antenatal care in Sioux Lookout, Ontario, showed that opioid use increased from $8 \%$ to $18 \%$ during the 18 -month study. Neonatal abstinence syndrome in infants exposed to opioids was $30 \%$ overall and $66 \%$ among infants born to women who used opioids daily. ${ }^{48}$ Of the children affected, only $7 \%$ required pharmacologic treatment, whereas the remainder received supportive care. ${ }^{48}$ Pilot studies are in progress in First Nations communities in Northwestern Ontario to investigate community-based provision of buprenorphine maintenance therapy where methadone is not available ${ }^{50}$ and to provide locally trained maternal support workers for women with opioid dependence during pregnancy and continuing until the child reaches 3 years of age. ${ }^{51}$

\section{Conclusion}

Although methadone is the gold standard for treatment of opioid dependency in pregnancy, methadone therapy is often not feasible in rural and remote settings. Proposed alternatives to methadone, such as opioid detoxification and slow-release morphine substitution, have limited evidence to support their use in pregnancy. Stronger evidence exists to support buprenorphine maintenance therapy.

A fundamental flaw of each study is the choice of birth as an end point. This enables reporting of nominal success rates in terms of abstinence at the time of delivery and neonatal abstinence syndrome. However, the true end

\begin{tabular}{|c|c|c|c|}
\hline \multirow[b]{2}{*}{ Reference } & \multirow[b]{2}{*}{ Protocol } & \multicolumn{2}{|c|}{ Outcomes at delivery } \\
\hline & & Maternal & Neonatal \\
\hline $\begin{array}{l}\text { Maas et al. } 1990^{42} \\
n=58\end{array}$ & $\begin{array}{l}\text { - Outpatient detoxification } \\
\text { lasting } 2-8 \mathrm{wk} \\
\text { - Individualized taper of } \\
0.2-1 \mathrm{mg} \text { of methadone daily }\end{array}$ & $\begin{array}{l}\text { - Abstinence: } 17 / 58 \\
\text { - MMT taper: } 8 / 58 \\
\text { - MMT taper with illicit drug use: } \\
\text { 32/58 } \\
\text { - Lost to follow-up: } 1 / 58\end{array}$ & $\begin{array}{l}\text { - Fewer NAS symptoms, lower } \\
\text { PTD rate, higher body weight, } \\
\text { longer pregnancies among } \\
\text { women who abstained, } \\
\text { followed by women who } \\
\text { underwent MMT, compared } \\
\text { with women who continued to } \\
\text { use heroin }\end{array}$ \\
\hline $\begin{array}{l}\text { Dashe et al. } 1998^{40} \\
n=34\end{array}$ & $\begin{array}{l}\text { Stabilization } \\
\text { - Clonidine: mild withdrawal } \\
\text { - Methadone: moderate to } \\
\text { severe withdrawal } \\
\text { Taper } \\
\text { - No more than } 20 \% \text { every } 3 \mathrm{~d} \\
\text {-3-39 d, median } 12 \text {-d inpatient } \\
\text { stay }\end{array}$ & $\begin{array}{l}\text { - Abstinence: } 59 \% \\
\text { - MMT: } 12 \% \\
\text { - lllicit drug use: } 29 \%\end{array}$ & $\begin{array}{l}\text { - NAS: } 44 \% \text { of infants showed } \\
\text { symptoms, } 15 \% \text { required } \\
\text { treatment } \\
\text { - PTD: no deliveries before } 36 \mathrm{wk} \\
\text { - Stillbirth: none }\end{array}$ \\
\hline $\begin{array}{l}\text { Luty et al. } 2003^{43} \\
n=101\end{array}$ & $\begin{array}{l}\text { - } 21 \text {-d inpatient methadone } \\
\text { taper } \\
\text { - } 51 \text { women lost to follow-up } \\
\text { - Complete records for } 24 \\
\text { women and } 22 \text { infants }\end{array}$ & $\begin{array}{l}\text { - Abstinence: } 1 / 24 \\
\text { - MMT and opiate use: not } \\
\text { documented } \\
\text { - Rehabilitation program } \\
\text { postpartum: none }\end{array}$ & $\begin{array}{l}\text { - NAS: Not documented } \\
\text { - PTD: 7/22 infants for whom } \\
\text { records were available } \\
\text { - Stillbirth: None }\end{array}$ \\
\hline $\begin{array}{l}\text { Jones et al. } 2008^{44} \\
n=123\end{array}$ & $\begin{array}{l}\text { 3-d methadone taper }(n=75) \\
- \text { Day 1, } 20 \mathrm{mg} \text {; day } 2,10 \mathrm{mg} ; \\
\text { day 3,10 mg } \\
\text { 7-d methadone taper }(n=48) \\
\text { - Day 1, } 30 \mathrm{mg} \text {; dose reduced by } \\
5 \mathrm{mg} \text { each day thereafter }\end{array}$ & $\begin{array}{l}\text { - Abstinence: } 47 \% \text { (3-d taper) } \\
\text { and } 43 \% \text { (7-d taper) } \\
\text { - MMT: } 11 \% \text { (3-d taper) and } 42 \% \\
\text { (7-d taper) } \\
\text { - Illicit drug use: } 53 \% \text { (3-d taper) } \\
\text { and } 57 \% \text { (7-d taper) vs. } 23 \% \text { in } \\
\text { control group receiving MMT }\end{array}$ & $\begin{array}{l}\text { - No difference between case } \\
\text { and control groups for NAS, } \\
\text { low birth weight or APGAR } \\
\text { scores }\end{array}$ \\
\hline $\begin{array}{l}\text { Stewart et al. } 2013^{41} \\
n=95\end{array}$ & $\begin{array}{l}\text { Stabilization } \\
\text { - Methadone dose based on } \\
\text { history of use and titrated up } \\
\text { based on withdrawal symptoms } \\
\text { Taper } \\
\text { - No more than } 20 \% \text { every } 1-3 \text { d }\end{array}$ & $\begin{array}{l}\text { - Abstinence: } 56 \% \\
\text { - MMT: } 18 \% \\
\text { - Illicit drug use: } 44 \%\end{array}$ & $\begin{array}{l}\text { - NAS: Lower Finnegan scores, } \\
\text { shorter stays in hospital and } \\
\text { less treatment } \\
\text { - PTD: No difference } \\
\text { - Stillbirth: } 2 \text { (mothers were } \\
\text { actively using heroin) }\end{array}$ \\
\hline
\end{tabular}


point is either sustained abstinence or stable opioid substitution therapy that would enable the new mother to parent her child. In this regard, the literature suggests that postpartum treatment is generally not provided to women in rural and remote communities, which contributes to high rates of relapse and apprehension of infants into custody. ${ }^{2,13,44}$

Despite knowledge of harm and rising rates of opioid dependence in pregnancy, there is a paucity of high-quality evidence in this area and none that specifically addresses the needs of rural and remote communities or Aboriginal communities, polysubstance use or postpartum management. There is an overwhelming need for training in opioid dependence therapy, regulatory changes to ensure pregnant women have access to appropriate medications and greater access to comprehensive treatment both during pregnancy and postpartum in rural and remote settings.

\section{References}

1. International Narcotics Control Board. Narcotic drugs technical report: estimated world requirements for 2013 - statistics for 2011. New York: United Nations; 2013.

2. Kaltenbach K, Berghella V, Finnegan L. Opioid dependence during pregnancy: effects and management. Obstet Gynecol Clin North Am 1998;25:139-51.

3. Fajemirokun-Odudeyi O, Sinha C, Tutty S, et al. Pregnancy outcome in women who use opiates. Eur J Obstet Gynecol Reprod Biol 2006;126:170-5.

4. Jones HE, Martin PR, Heil SH, et al. Treatment of opioiddependent pregnant women: clinical and research issues. J Subst Abuse Treat 2008:35:245-59.

5. Winklbaur B, Kopf N, Ebner N, et al. Treating pregnant women dependent on opioids is not the same as treating pregnancy and opioid dependence: a knowledge synthesis for better treatment for women and neonates. Addiction 2008;103:1429-40.

6. Borders TF, Booth BM. Research on rural residence and access to drug abuse services: Where are we and where do we go? J Rural Health 2007;23(Suppl):79-83.

7. Canadian Task Force on Preventive Health Care. New grades for recommendations from the Canadian Task Force on Preventive Health Care. CMAJ 2003;169:207-8.

8. What's urban? What's rural? Ottawa: Statistics Canada. Available: www41.statcan.ca/2006/3119/ceb3119_002-eng.htm (accessed 2014 Apr. 21].

9. Buske L. Rural reality: analyzing medical life outside Canada's cities. Ottawa: Canadian Medical Association; 2008.

10. Shannon LM, Havens JR, Hays L. Examining differences in substance use among rural and urban pregnant women. Am J Addict 2010;19:467-73.

11. Heil SH, Sigmon SC, Jones HE, et al. Comparison of characteristics of opioid-using pregnant women in rural and urban settings. Am J Drug Alcohol Abuse 2008;34:463-71.

12. Wong S, Ordean A, Kahan M. Substance abuse in pregnancy. J Obstet Gynaecol Can 2011;33:367-84.

13. American College of Obstetricians and Gynecologists. Opioid abuse, dependence and addiction in pregnancy. Committee opinion 254. Obstet Gynecol 2012;119:1070-71.

14. Methadone program. Ottawa: Health Canada; 2011. Available: www.hc-sc.gc.ca/hc-ps/substancontrol/exemptions/methadone-eng .php (accessed 2013 July 29).

15. Section 56 class exemption for pharmacists. Ottawa: Health Canada; 2011. Available: www.hc-sc.gc.ca/hc-ps/substancontrol /pol/pol-docs/exemp pharm-eng.php (accessed2013 July 29).

16. Lacroix I, Berrebi A, Garipuy D, et al. Buprenorphine versus methadone in pregnant opioid-dependent women: a prospective multicenter study. Eur J Clin Pharmacol 2011;67:1053-9.

17. Welle-Strand GK, Skurtveit S, Jones HE, et al. Neonatal outcomes following in utero exposure to methadone or buprenorphine: a national cohort study of opioid-agonist treatment of pregnant women in Norway from 1996 to 2009. Drug Alcohol Depend 2013;127:200-6
18. Fischer G, Ortner R, Rohrmeister K, et al. Methadone versus buprenorphine in pregnant addicts: a double-blind, doubledummy comparison study. Addiction 2006;101:275-81.

19. Jones HE, Kaltenbach K, Heil SH, et al. Neonatal abstinence syndrome after methadone or buprenorphine exposure. $\mathrm{N} \mathrm{Engl}$ J Med 2010;363:2320-31.

20. Debelak K, Morrone WR, O'Grady KE, et al. Buprenorphine + naloxone in the treatment of opioid dependence during pregnancy-initial patient care and outcome data. Am J Addict 2013;22:252-4

21. Potter JS, Marino EN, Hillhouse MP, et al. Buprenorphine/naloxone and methadone maintenance treatment outcomes for opioid analgesic, heroin, and combined users: findings from starting treatment with agonist replacement therapies (START). J Stud Alcohol Drugs 2013;74:605-13.

22. Hser YI, Saxon AJ, Huang D, et al. Treatment retention among patients randomized to buprenorphine/naloxone compared to methadone in a multi-site trial. Addiction 2014; 109:79-87.

23. Hanford C. Buprenorphine/naloxone for opioid dependence: clinical practice guideline. Toronto: Centre for Addiction and Mental Health; 2012.

24. Lund IO, Fischer G, Welle-Strand GK, et al. A comparison of buprenorphine + naloxone to buprenorphine and methadone in the treatment of opioid dependence during pregnancy: maternal and neonatal outcomes. Subst Abuse 2013;7:61-74.

25. Daily Med. Naloxone hydrochloride [product monograph]. Bethesda (MD): National Institutes of Health; 2013. Available: http://dailymed.nlm.nih.gov/dailymed/lookup.cfm?setid $=d 524 c 0 e 5$ -a7c2-40b2-9eed-2caf71c787dc (accessed 2013 Aug. 23).

26. Daily Med. Suboxone tablet [product monograph]. Bethesda (MD): National Institutes of Health; 2013. Available: http://dailymed.nlm .nih.gov/dailymed/lookup.cfm? setid=4b9b43c4-293e-4323-alal -9a2f6al6ac39. (accessed 2013 Aug. 23)

27. Daily Med. Suboxone soluble film [product monograph]. Bethesda (MD): National Institutes of Health; 2013. Available: http://dailymed.nlm.nih.gov/dailymed/lookup.cfm?setid=8a5edcf9 -828c-4f97-b671-268ab13a8ecd(accessed 2013 Aug. 23)

28. Chase C. Supporting women using opiates in pregnancy: a guideline for primary care providers. Toronto: The Centre for Addiction and Mental Health Knowledge Exchange; 2011. (accessed 2013 Aug. 11). Available: http://knowledgex.camh .net/opioid_alert/2012/Documents/supporting_women_opiates _pregnancy511.pdf

29. Fischer G, Jagsch R, Eder H, et al. Comparison of methadone and slow-release morphine maintenance in pregnant addicts. Addiction 1999;94:231-9.

30. Schneider C, Fischer G, Diamant K, et al. Pregnancy and Drug Dependence. Wien Klin Wochenschr 1996;108:611-4.

31. Etzersdorfer P, Fischer G, Eder H, et al. Comparison of morphine and methadone maintenance in pregnant opiate addicts. NIDA Res Monogr 1997;178:343.

32. Ornoy A, Michailevskaya V, Lukashov I, et al. The developmental outcome of children born to heroin-dependent mothers, raised at home or adopted. Child Abuse Negl 1996;20:385-96.

33. McCarthy JJ, Leamon MH, Parr MS, et al. High-dose methadone maintenance in pregnancy: maternal and neonatal outcomes. Am J Obstet Gynecol 2005;193:606-10.

34. Cleary BJ, Eogan M, O'Connell MP, et al. Methadone and perinatal outcomes: a prospective cohort study. Addiction 2012; 107:1482-92.

35. Albright B, de la Torre L, Skipper B, et al. Changes in methadone maintenance therapy during and after pregnancy. $J$ Subst Abuse Treat 2011;41:347-53.

36. Blinick G, Wallach RC, Jerez E. Pregnancy in narcotics addicts treated by medical withdrawal. The methadone detoxification program. Am J Obstet Gynecol 1969;105:997-1003.

37. Rementeriá JL, Nunag NN. Narcotic withdrawal in pregnancy: stillbirth incidence with a case report. Am J Obstet Gynecol 1973; 116:1152-6.

38. Stern R. The pregnant addict: a study of 66 case histories, 1950-1959. Am J Obstet Gynecol 1966;94:253-7.

39. Dashe JS, Sheffield JS, Olscher DA, et al. Relationship between maternal methadone dosage and neonatal withdrawal. Obstet Gynecol 2002;100:1244-9.

40. Dashe JS, Jackson GL, Olscher DA, et al. Opioid detoxification in pregnancy. Obstet Gynecol 1998;92:854-8.

41. Stewart RD, Nelson DB, Adhikari EH, et al. The obstetrical and neonatal impact of maternal opioid detoxification in pregnancy. Am J Obstet Gynecol 2013;209:267.e1-5.

42. Maas U, Kattner E, Weingart-Jesse B, et al. Infrequent neonatal opiate withdrawal following maternal methadone detoxification during pregnancy. J Perinat Med 1990;18:111-8.

43. Luty J, Nikolaou V, Bearn J. Is opiate detoxification unsafe in pregnancy? J Subst Abuse Treat 2003;24:363-7. 
44. Jones HE, O'Grady KE, Malfi D, et al. Methadone maintenance vs. methadone taper during pregnancy: maternal and neonatal outcomes. Am J Addict 2008;17:372-86.

45. Finnegan LP. Treatment issues for opioid-dependent women during the perinatal period. J Psychoactive Drugs 1991;23: 191-201.

46. Kaltenbach K, Berghella V, Finnegan L. Opioid dependence during pregnancy. Effects and management. Obstet Gynecol Clin North Am 1998;25:139-51.

47. Uddin F. Hope in Fort Hope: First Nations community is winning the battle against prescription drug abuse. Can Fam Physician 2013;59:391-3.

48. Kelly L, Dooley J, Cromarty H, et al. Narcotic-exposed neonates in a First Nations population in Northwestern Ontario: incidence and implications. Can Fam Physician 2011;57:e441-7.

49. Kiepek N, Hancock L, Toppozini D, et al. Facilitating medica withdrawal from opiates in rural Ontario. Rural Remote Health 2012;12:2193.

50. Webster PC. Indigenous Canadians confront prescription opioid misuse. Lancet 2013;381:1447-8.
51. First Nations maternal support worker program first of its kind. Meno Ya Win News [Sioux Lookout (ON)] 2013;11:1-2.

Affiliations: Thunder Bay Regional Research Institute, Thunder Bay, Ont., and Department of Obstetrics and Gynaecology (Jumah), University of Toronto, Toronto, Ont.; Department of Family Medicine (Graves), Northern Ontario School of Medicine, Sudbury, Ont.; Department of Family and Community Medicine, University of Toronto, and Substance Use Service, Women's College Hospital (Kahan), Toronto, Ont.

Contributors: Naana Afua Jumah was responsible for the primary literature review, the analysis and interpretation of data and the drafting and revising of the article. Lisa Graves and Meldon Kahan contributed to the analysis and interpretation of the data and revised the article for important intellectual content. All of the authors approved the final version submitted for publication and agree to act as guarantors of the work. 